\title{
UNIVERSITYOF
}

FORWARD

THINKING

WESTMINSTER用

WestminsterResearch

http://www.westminster.ac.uk/westminsterresearch

Farmers as experts: interpreting the "hidden" messages of

participatory video across African contexts

Snyder, K., Cullen, B. and Braslow, J.

This is the peer reviewed version of the following article: Snyder, K., Cullen, B. and Braslow, J. (2019) Farmers as experts: interpreting the "hidden" messages of participatory video across African contexts, Area: Journal of the Royal Geographical Society, DOI: 10.1111/area.12538, which has been published in final form at:

https://dx.doi.org/10.1111/area.12538.

This article may be used for non-commercial purposes in accordance with Wiley Terms and Conditions for Self-Archiving.

The WestminsterResearch online digital archive at the University of Westminster aims to make the research output of the University available to a wider audience. Copyright and Moral Rights remain with the authors and/or copyright owners.

Whilst further distribution of specific materials from within this archive is forbidden, you may freely distribute the URL of WestminsterResearch: ((http://westminsterresearch.wmin.ac.uk/)).

In case of abuse or copyright appearing without permission e-mail repository@westminster.ac.uk 


\section{Farmers as experts: interpreting the 'hidden' messages of participatory video across African contexts}

\begin{tabular}{|c|c|}
\hline Journal: & Area \\
\hline Manuscript ID & AREA-RP-Feb-2018-0015.R2 \\
\hline Manuscript Type: & Regular Paper \\
\hline Keywords: & Participatory Video, Participation, Empowerment, Africa \\
\hline Abstract: & $\begin{array}{l}\text { Recent scholarship has contributed important insights into the political } \\
\text { dynamics inherent in the process of making and showing participatory } \\
\text { videos (PV). As a research method and an instrument for social change, } \\
\text { participatory video has both potential and limitations for overturning the } \\
\text { power dynamics embedded within research and in development } \\
\text { processes. This paper focuses on experiences of incorporating } \\
\text { participatory video in land management projects in four countries in } \\
\text { Africa. Along with other participatory methods, the videos represented } \\
\text { an effort to include community perspectives and objectives into the } \\
\text { research process. Analysis of PV has largely focused on examining the } \\
\text { tensions and contradictions involved in the process of making } \\
\text { participatory videos. There has been less focus on the content of the } \\
\text { videos themselves and what it might suggest for empowerment, voice } \\
\text { and representation. This paper attempts to address this gap by } \\
\text { examining the implications of the narratives that emerge in five different } \\
\text { videos. On the surface, the participants appear to repeat dominant } \\
\text { national and global narratives about land degradation. However, the fact } \\
\text { that farmers present themselves as experts on these topics and the ways } \\
\text { in which they appropriate and reconfigure the dominant narratives, can } \\
\text { be seen as an act of empowerment. In this way, they preclude the need } \\
\text { for external intervention on how to manage their resources. }\end{array}$ \\
\hline
\end{tabular}

\section{SCHOLARONE" \\ Manuscripts}




\section{FARMERS AS EXPERTS: INTERPRETING THE ‘HIDDEN’ MESSAGES OF PARTICIPATORY VIDEO ACROSS}

\section{AFRICAN CONTEXTS}

Participatory video (PV) has gained attention in the last decade and is of increasing interest and use globally in both academic research and in development and social justice projects. Several critical papers (Kindon, 2003; Mistry and Berardi, 2012; Wynne-Jones et al, 2015; Plush, 2015; Kindon 2016; Milne, 2016; Mistry et al 2016; Rogers, 2016; Shaw, 2016; Walsh, 2016) have shed light on the nuances of power embedded in participatory video exercises and the limitations of the method for achieving social change (Tremblay and Harris, 2018). Walsh (2016), Shaw (2016) and Mistry et al, (2016) have all called for more nuanced analyses of power dynamics inherent in producing participatory videos and have underlined the importance of understanding the multiple objectives of all those involved. This body of literature, while still small, has begun an important debate on the usefulness of PV and its ability to challenge inherent power differences.

PV aims to enable participants to represent themselves and to identify what they think are important issues in their lives. The assumption underlying PV is that by allowing people to speak for themselves, rather than having researchers or development agents speak for them, their capacity to influence decisions shaping their lives will be improved (Lunch and Lunch, 2006; Milne et al, 2012; White, 1996; Wheeler, 2011; Mistry et al, 2016). The PV process is considered empowering because it fosters reflection on problems and enables participants to develop the voice to present those problems. Although amplifying voice and taking control over representation are critical steps in empowerment, these features on their own do not, in and of themselves, address underlying structural drivers of inequality. Indeed, conceptualising PV primarily in terms of voice and representation has been problematised as contributing to problems such as co-option and the dilution of transformative possibilities (Shaw, 2012; Shaw 2015a). 
Recent analysis of PV has done a great deal to highlight several challenges, including: the limitations of video leading to social change; individual versus community empowerment; the tendency of videos to perpetuate simplified notions of community through the presentation of homogeneous "community voice"; and the institutional constraints present in development projects (Kindon, 2003; Mistry and Berardi, 2012; Wynne-Jones et al, 2015; Plush, 2015a, 2015b; Kindon 2016; Milne, 2016; Mistry et al 2016; Rogers, 2016; Shaw, 2016; Walsh, 2016). As with participatory approaches more broadly, there is a risk that PV may "render technical" complex political and social problems and so overlook systemic power relations and thus re-produce rather than challenge dominant norms (Cooke and Kothari, 2001; Ferguson, 1990; Li, 2007; Leal, 2011; Mosse, 2011). While recent PV literature has analysed the process of making videos, there has been less attention directed to the actual products emerging from PV initiatives and what they might tell us. As Baselga (2015) notes, few theoretical works acknowledge the importance of PV as a specific form of audiovisual product. This is perhaps, in part, because the methodology intentionally places an emphasis on process rather than product.

This paper reflects on the content of video outputs emerging from PV processes across four countries in Sub-Saharan Africa. We analyse the explicit and implicit messages contained within the videos and argue that these messages, or narratives, shed light on development dynamics. A focus on narratives is nothing new, development literature abounds with references to and critiques of 'narratives of development' and the practices they promote (Roe, 1991). Carr (2010) indicates that narratives, or stories, can provide a way of understanding people's experiences of development and their encounters with development professionals. Mistry et al (2015) also illustrate that focusing on "what is in" audiovisual material produced by PV participants provides a way of exploring nuanced community narratives. 
With this in mind, we believe that outputs emerging from PV provide a particularly interesting window into investigating issues of politics, power and representation.

The videos that form the basis of our analysis were all made by farmers in the context of sustainable land management projects, an arena where the figure of the expert and notions of expert knowledge loom large (Assche et al, 2017; Chambers, 1983; Sillitoe, 2017). PV was intended to provide an opportunity for farmers to describe their land management challenges and suggest their own solutions. Reflecting on the PV process combined with our own knowledge of the context, gained over a multi-year time period, pertinent issues emerge. Particular attention is paid to how farmers represent themselves "on screen" in the context of dominant discourses on land management. We explore what these narratives might reveal about relations between farmers and "experts" and argue that although the videos may appear to repeat dominant narratives, there is often rather more going on beneath the surface than meets the eye. In making the videos, the participants are producing both explicit and implicit messages for local and global viewers in order to assert their own roles as experts on land management problems.

\section{THE PROCESS}

From 2011 to 2016, multidisciplinary teams carried out field research on sustainable land management projects in Ethiopia, Malawi, Ghana and Tanzania. ${ }^{1}$ These projects investigated the drivers of land-use management decisions and the constraints to adoption of more sustainable choices. Thus engagement with farmers, as primary land managers, was central throughout the projects. PV was one of a number of participatory methods deployed which also included transect walks, participatory mapping, and various ranking and sorting exercises carried out with community members. Other qualitative methods included interviews, focus groups, institutional analysis, and historical timelines. Household surveys 
produced quantitative data on farm production and basic social and economic data. Biophysical scientists carried out land use/land cover studies and soil analysis.

The inclusion of PV aimed to address the lack of farmer-voiced perspectives on land use and to overturn the "rule of experts" (Mitchell, 2002) so common in development projects. It aimed to bring local solutions to locally identified problems into the discussion on land management challenges. Because the projects had engaged with rural communities over the course of three years, the PV participants were very familiar with project goals to address land degradation. The videos produced, not surprisingly, focused on the central topic of land use. Thus, the content, from the start, was in part pre-determined, which veers from the ideal of PV. We also could not have justified producing videos on any given topic proposed by communities, particularly as the PV process was undertaken by international research institutions operating under agreements with host governments. This demonstrates how funding arrangements and institutional agendas modify how PV is implemented (Plush 2015b).

In Ethiopia, the video-making process took place with twelve participants over ten days in Fogera district in Amhara Region, an area north of the city of Bahir Dar. It was integrated into multi-stakeholder platforms created by the project to bring different interest groups together to discuss land management challenges and design joint solutions. We felt that PV could provide a way for farmers to present their views, believing that they, as Wheeler (2011) also suggests, are more knowledgeable about their realities.

None of the participants had ever used a camera before so we used games and exercises to teach rudimentary camera skills before progressing to video production, interviewing, presentation and sequence shooting. The research team facilitated the process of issue selection. Once the issues, 
Following the video-making process, over the course of several weeks, participants reviewed the edited film and, after a process of informed consent, it was screened to members of the wider community in each of the districts. Viewers then discussed the content of the film, responded to it and added their views, which were recorded by the PV participants. This enabled other members of the wider community to comment, disagree and suggest alterations. A version of the film was screened to members of the research project at an internal screening in Addis Ababa to get feedback. The final film was then screened to members of the Fogera stakeholder platform that included district administrators, agricultural extension agents and experts from national research institutes. After the video was shown and discussed, platform members were interviewed and their responses were filmed.

In Ghana, Malawi and Tanzania, the process was similar to that described for Ethiopia, with one key difference: because of institutional pressures, the video making process was shortened to six days rather than ten due to constraints in time and funding. In these countries, a team of researchers from an international research institution together with local university partners facilitated the process. In all countries, an equal number of men and women, ranging from nine to twelve total participants, comprised the community teams that made the videos. The process followed the same sequences and involved playback throughout all days for participants to assess the content and make any changes they wanted going forward. The videos were screened to the wider community in which they took place and to district level planners and implementers, researchers outside of the project, NGOs, and national level policy makers and officials. These screenings and responses from viewers were not filmed and included 
in the final video, again because of time and logistical constraints (available light, etc.), but a record was taken of responses.

International researchers and local counterparts facilitated the PV process. National partners (extension officers and researchers from national institutes) chose the participants from the local communities, using certain criteria - on gender, socio-economic status, and age - in an effort to reflect community composition. This strategy was obviously problematic as adequate representation in a small group is not really possible given the diversity within rural communities. Additionally, national partners tended to choose farmers that they had worked with in the past or who they thought best able to carry out the task. In all countries, perceptions about who was best placed to participate was usually based on an individual's status in the community, their knowledge, and an ability to "speak well". So, in Tanzania, we had some local leaders, members of women's groups, an extension officer and other fairly successful farmers. In Upper East Ghana, there was a local chief and an assemblyman and a mixture of community members who had engaged in past projects. In Ethiopia, there was a "model farmer", members of local women's groups and the leader of a government initiated youth group.

The video making process in each of the countries followed a short-term, 'single-loop' process (Shaw, 2015), in many ways comparable to models of "shallow participation" outlined by Cornwall and Jewkes (1995). We found it difficult to implement, longer and more engaged “double-loop" processes due to the time and budgetary constraints of the respective projects. We were cognizant of the fact that the PV literature indicates that one round of video-making tends to reproduce dominant norms and indeed, on the surface, each of the videos appears to do just that. However, the video products also captured valuable insights into development dynamics in each of the respective countries. With this in mind, we have analysed the video outputs with the aim of highlighting some of the underlying, but often hidden 
messages. This analysis focused on how dominant narratives are communicated, through participants' oration, through skits and characters in these skits, and the messages highlighted in on-screen interviews. We looked for key words, topics and themes from ongoing national debates on land-use. Each video emphasizes specific messages, related to land management dynamics of the respective country, with which both national level decision-makers and local community members are familiar.

\section{MAKING THE VIDEOS - EMERGENT NARRATIVES}

In discussions about what challenges land users face, what affects their decisions and what they see as the most important issues to highlight, participants unsurprisingly selected topics that were already part of district or national discussion and dominant development agendas, and were linked in various ways to the specific socio-political and historical contexts of each country.

In northern Ghana (https://www.youtube.com/watch?v=8hw4ytnCU6A\&t=1s, https://www.youtube.com/watch?v=RrZQt3dHJoA), bush burning was a prominent theme. This issue has dominated agricultural development and environmental management programs from the colonial era onwards. Amanor's (2002) illuminating overview of colonial and post-colonial policies and practices regarding burning, describes how the scientific literature from the 50 s and 60 s that questioned the validity of banning fire, has been superseded by publications advocating for its eradication. NGOs and government widely promote programs to address "peasant backwardness" and their "entrenched cultural beliefs" on burning (Amanor, 2002: 67-69). While more recent research, particularly in Mali (Laris, 2002; Laris and Wardell, 2006), indicates that mosaic burning across the landscape has significant benefits, this work has not gained traction in the way that anti-fire narratives have. The discourse surrounding farmer ignorance and backwardness has clearly penetrated rural communities: 


\begin{abstract}
Many of the youth.....have been educated in schools about the cultural ills of fire. They have become intolerant of the use of fire, which they consider to be culturally backward and rustic. Since the anti-bushfire discourse strengthens the power of chiefs and the District Assembly over the rural population they have become firm converts to its objectives (Amanor, 2002: 71).
\end{abstract}

\begin{abstract}
In the videos, bush burning and its negative consequences figure as central concerns. Interestingly, community members chose to reiterate and appropriate dominant narratives that have long been used to undermine local practices and knowledge, rather than counter them. As the project concerned sustainable land management, it is hardly surprising that community participants chose to draw upon
\end{abstract} well-established narratives. Burning is presented as a threat to livelihoods by decreasing soil quality and damaging valuable tree species. Like external experts, either foreign or domestic, the video makers admonish their fellow farmers to abandon practices of burning and tree cutting. Interpreting these positions is hardly straightforward, but it could be argued that the video makers, by adopting the antibush burning discourse assert their own role as "experts". They adopt both the language of experts in their reference to soil quality but also in their disapproval and instruction against "bad practices". In so doing, they preclude the need for external experts by emphasizing their own "local" knowledge of the negative consequences of burning. These narratives can serve two purposes depending on the audience. For external viewers, they suggest "awareness raising" by outsiders is not necessary. For internal audiences, the video-makers, who included a local chief, strengthen their authority by proclaiming their role as communicators of national messages.

Whilst videos from all four countries drew attention to issues surrounding trees, the video made in Malawi was perhaps the most focused on issues of deforestation. This reflects politically charged debates that have generated both crisis narratives and counter-narratives (Zulu, 2010). In the video, 
farmers depict the cutting of trees for firewood or charcoal or clearing land, and the need to plant and preserve them, but place particular emphasis on the link between tree cover and poverty. Entitled "Let's Conserve the Environment by Finding Solutions to Poverty"

(https://www.youtube.com/watch?v=0EZD5Iv_xAQ), it details, in a skit, how people struggle to produce enough food, or the cash to buy food, so they often turn to charcoal production. In the skit, a woman arrives on the scene of a family cutting down a tree and tells them to stop destroying the environment. She admonishes them saying "the government and NGOs are against this practice". The woman who is cutting down the tree exclaims, "I thought you were going to talk about food. That is what we need!" Although they promote the dominant message about preserving trees, the Malawi video participants emphasize that poverty is the root of their problem and is what drives people to degrade their environment. As one of the women states, "Of course people understand but they lack alternatives and depend on the trees as a primary source of income". The participants urge NGOs and government to help them find solutions to their poverty and to provide training in technical skills which will relieve their dependence on the environment for their livelihood.

In Ethiopia, the video makers also repeat dominant government narratives, in this case about "free grazing" and land degradation. Since the 1990s, the implementation of soil and water conservation (SWC) measures has been undertaken as part of the government's agricultural extension package (Bewket, 2007). In the north of Ethiopia, particular emphasis has been on restricting livestock grazing to prevent damage to physical SWC structures. In the video, despite repeating certain narratives, farmers also warn of the consequences of restricting grazing for marginalized community members who rely on communal grazing areas for fodder and collection of dung cakes for fuel. Ethiopia is a particularly acute example of top-down, hierarchical planning and implementation (Snyder et al, 2014). Indeed, many "experts" assume that farmers' "ignorance" and "poor" decision-making is at the root of land 
degradation and challenges to agricultural production (Rahmato, 2006). However, the restrictive political situation inhibits farmer voice and as a result they are not able to openly express critical opinions of government initiatives. Although participants voiced critical opinions behind the scenes during the video making process, the narratives that feature in the video are deliberately measured. Farmers express the pros and cons of restricting grazing and emphasize that efforts to solve natural resource management problems should start with communities. In their balanced approach, farmers mirror narrative strategies commonly used by politicians and other powerful "experts", thereby positioning themselves as people who know and can also "speak well".

In Tanzania (https://www.youtube.com/watch?v=ErjbvNr15jY), the video team performed a skit, highlighting the difference between a "poorly" managed farm where the farmer continued to carry out practices from "their grandfather's time" doing little to conserve soil on steep slopes. This field is contrasted with that of a neighboring farmer who practices "expert" (kitaalamu) farming by constructing terraces and planting trees. They explained that "experts" taught them these practices and that their land has become more productive because of them. The juxtaposition of "traditional" with "modern" is a very common and longstanding theme in Tanzania, particularly pertaining to farming (Bishop, 2007; Raikes, 1978). The central figure in the skits is the extension officer, farmers appear as largely voiceless and submissive characters, often standing in the background and nodding their agreement. The team visits the extension officer's compound where he practices agriculture as a "business". The video tours his farm, focusing on the abundant maize harvest, the "modern", stall-fed cows and goats and the "Israeli" chickens. Adopting "modern" (ya kisasa) farming practices is a central message of the video and a widely circulated national preoccupation. Repeating national narratives allows the video makers to assert themselves as "modern" and already carrying out the practices that "experts" recommend. Yet, as one farmer asks the extension officer, "If we wanted goats, chickens or 


\section{DISCUSSION}

On the surface, the videos may repeat the dominant development discourse, but they also contain layered narratives and multiple meanings, if you know what to look for or "read". The videos capture dynamics that may not be apparent without knowledge of the context in which they are located. For example, knowledge of the history of bush burning and its continued prevalence in national discourse, knowledge of government-community relationships and interactions, knowledge of what "development" means in the national imaginary, are all contextual knowledge that the researchers gained working in these countries for several years and drew upon in analysing the video content. Every video viewer will have different knowledge of and interpretations of these contexts. This raises some questions: what do different audiences see when they watch these videos? Are there forms of resistance to, or subversion of, dominant development narratives within the videos that may not be immediately apparent to everyone who watches them? Mitchell (2011), for example, highlights that PV outputs can carry a "double message, or meta-message" which may serve to reveal alternative narratives and express concerns. Analysis of PV, then, would benefit from an examination of these underlying messages and this perhaps demands a more nuanced understanding on the part of PV facilitators that multiple messages may evoke multiple readings.

This element of "double messages" can be seen, in particular, in the performative segments included in the videos. The skits present characters acting out common development scenarios and dialogues. Through this performative process, PV perhaps provides a space to act out alternative realities and 
subvert dominant power dynamics. For example, a woman in the Malawi video confronts a Forest Officer, even going so far as threatening him with a machete saying, "You! Don't talk so much, otherwise I will hack you. With the hunger situation we have this year, this is the only option we have to survive". This is something she would be extremely unlikely to do in real life. The amusement on the part of her fellow participants is notable and you can imagine the amusement during community video screenings when audiences see a fellow farmer taking on a government official. Waite \& Conn (2011) suggest that humor can be read as a subtle source of resistance, which makes it no less powerful than other techniques, and indeed may have even more of an impact on an audience.

Most of the videos focused on the complexities of the problems they highlighted and emphasized internal measures to take and where, when and how external support was wanted. In Upper East region of Ghana, the participants chose to highlight actions that community members could take themselves (such as manure and crop residue incorporation, building stone bunds, protecting trees) and emphasized that outside assistance was not really needed. This choice to emphasize internal agency versus reliance on external assistance was carefully chosen by the participants during their deliberations on the main messages they wanted to convey. In Malawi, the video makers focused on how the wider context of poverty drives local actions. They called on government to build local capacity to pursue livelihoods not dependent on land use. In Ethiopia, the participants state in no uncertain terms, "it is us who should find the solutions for our problems... the solution is with ourselves".

The relationship of local communities to external experts emerges in most of the. By repeating dominant narratives, the video makers are presenting themselves as experts and suggesting that they do not need further instruction on how to implement sustainable land management practices. Where the video makers do want expert assistance is in accessing resources that go beyond what is available in 
In all of the cases described above, participants wanted their videos to be shared broadly. Indeed, they hoped they would be seen globally and wanted them posted on YouTube. The videos were shown locally to district officials, NGOs, and decision makers in each country, in the context of multi-stakeholder platforms. The stakeholders were already familiar with the projects, as researchers had been interacting with them over the course of a few years. When we invited them to the screenings, we explained that communities had made videos about their land use issues and wanted a wide audience to view them. How the messages were received by the various people who viewed, and continue to view the videos, is obviously varied. In our observation, when we showed the videos to local development professionals, they rarely focused on the content, despite attempts to facilitate discussion following the screenings. Rather, they often expressed interest and even surprise that community members had been able to master the technology and to make a video on their own. Although some viewers seemed impressed by community members' in-depth knowledge of the problems they described, this did not generate 
meaningful discussion between PV participants and "experts". In one sense, this reaction, or lack thereof, is not surprising given that what video-makers emphasized is that they already have knowledge, what they need is more tangible assistance for certain specific problems. Often, this tangible assistance is beyond what decision-makers are able to implement, due to funding and other constraints.

\section{CONCLUSION}

The videos in this project intended to provide an opportunity for land users themselves to describe their challenges and to suggest their own solutions to them. How well did these videos achieve that goal? All the videos clearly highlight existing land-use issues that external experts have raised for a long time, from free grazing in Ethiopia to tree cutting and soil erosion. They all illustrate that local community members know the common narratives around land management challenges very well. The videos also suggest that knowledge alone is clearly not enough to address practices that degrade the environment. As long as poverty continues and farming and livestock herding options continue to become more limited, resources will remain under threat. In this way, these videos suggest that unless underlying political and economic factors change, people will do what they can to provide for their families and that may mean degrading natural resources, but this does not mean that they lack awareness or knowledge. While the projects lacked the time and resources to facilitate a deeper dialogue between farmers and decision-makers, development actors, whether in NGOs or in government are well aware of poverty being an essential driver. Actually addressing poverty remains a challenge.

Participatory methods provide ways for community members to "perform" their roles as "citizens" and to represent "community knowledge" (Kothari, 2001; Kesby, 2005; Green, 2009). Green further argues that in so participating, they "produce a representation of knowledge as a community product and thus community as an object of government" (2009:18). This simplified version of community knowledge 
What these video narratives demonstrate is the ways in which this method can shed light on new forms of knowledge, ones that combine messages promoted in national and global narratives on land degradation and ones that have emerged from local land-users' experience over time. They also implicitly convey community knowledge of the broader agendas, power dynamics and politics at play in development processes and where they fit within this context. One could interpret the video-makers' messages as examples of resistance - resistance to the perception that rural people lack knowledge. Nuanced analysis of the messages that emerge from short-term, single-loop participatory video processes may provide a useful starting point for longer-term, more engaged PV processes, and offer a compelling and powerful argument for the inclusion of these processes within land management initiatives. 


\section{REFERENCES}

Amanor, K. S. (2002). Bushfire management, culture and ecological modernisation in Ghana. IDS Bulletin, $33(1), 65-74$.

Assche, K., Beunen, R. \& Duineveld, M. (2017). The will to knowledge: natural resource management and power/knowledge dynamics. Journal of environmental policy \& planning, 19 (3), 245 - 250.

Baselga. S. (2015). Can we study participatory video within film studies? A succinct approach. Glocal Times, 22/23, $1-9$.

Bewket, W. (2007). Soil and water conservation intervention with conventional technologies in northwest highlands of Ethiopia: Acceptance and adoption by farmers. Land Use Policy, 24 (2), $404-416$.

Bishop, E. (2007). Schooling and the encouragement of farming amongst pastoralists in Tanzania. Nomadic Peoples, 9-29.

Carr, E. (2010). The place of stories in development: creating spaces for participation through narrative analysis. Development in practice, 20 (2), $219-226$.

Chambers, R. (1983). Rural development: putting the last first. Harlow: Prentice Hall.

Cleaver, F. (1999). Paradoxes of participation: questioning participatory approaches to development. Journal of international development, 11(4), 597. 
Cooke, B., \& Kothari, U. (Eds.). (2001). Participation: The new tyranny?. Zed books.

Cornwall, A., \& Jewkes, R. (1995). What is participatory research?. Social science \& medicine, 41(12), $1667-1676$.

Green. M. (2017). Dairying as development: caring for "modern" cows in Tanzania. Human organization, 76 (2), 109-120.

Green, M. (2009). Government through time: participation and poverty reduction in Tanzania. Chronic poverty research centre (CPRC).

Hickey, S., \& Mohan, G. (2004). Participation--from tyranny to transformation?: Exploring new approaches to participation in development. Zed books.

Kesby, M. (2005). Re-theorizing empowerment-through-participation as a performance in space: Beyond tyranny to transformation. Signs: journal of women in culture and society, 30(4), 2037-2065.

Kindon, S. (2016). Participatory video's spectro-geographies. Area, 48(4), 449-451.

Kindon, S. (2003). Participatory video in geographic research: a feminist practice of looking?. Area, 35(2), 142-153.

Laris, P., \& Wardell, D. A. (2006). Good, bad or "necessary evil"? Reinterpreting the colonial burning experiments in the savanna landscapes of West Africa. The geographical journal, 172(4), 271-290. 
Laris, P. (2002). Burning the seasonal mosaic: preventative burning strategies in the wooded savanna of southern Mali. Human ecology, 30(2), 155-186.

Lunch, N., \& Lunch, C. (2006). Insights into participatory video: A handbook for the field. InsightShare.

Milne, E. J. (2012). Saying "no" to participatory video. Handbook of participatory video, 257.

Mistry, J., Bignante, E., \& Berardi, A. (2016). Why are we doing it? Exploring participant motivations within a participatory video project. Area, 48(4), 412-418.

Mistry, J., Berardi, A., Tschirhart, C., Bignante, E., Haynes, L., Benjamin, R., \& de Ville, G. (2015). Indigenous identity and environmental governance in Guyana, South America. Cultural geographies, 22(4), 689-712.

Mistry, J., \& Berardi, A. (2012). The challenges and opportunities of participatory video in geographical research: exploring collaboration with indigenous communities in the North Rupununi, Guyana. Area, 44(1), 110-116.

Mitchell, C. (2011). What's Participation got to do with It? Visual methodologies in 'Girl-Method' to address gender-based violence in the time of AIDS. Global studies of childhood, 1 (1), $51-59$.

Mitchell, T. (2002). Rule of experts: Egypt, techno-politics, modernity. Univ of California Press. 
Plush, T. (2015a). Participatory video and citizen voice-We've raised their voices: is anyone listening?. Glocal times No. 22/23 (September 2015), 1-15.

Plush, T. (2015b). Interrogating practitioner tensions for raising citizen voice with participatory video in international development. Nordicom review, 36(Special Issue), 57-70.

Rahmato D. (2003). Littering the landscape: environmental policy in northeast Ethiopia. In African Savannas: Global Narratives and Local Knowledge of Environmental Change, Bassett T, Crummey D (eds). James Currey: Oxford; 205-224.

Raikes, P. (1978). Rural differentiation and class-formation in Tanzania. The Journal of peasant studies, 5(3), 285-325.

Roe, E. (1991). Development narratives, or making the best of blueprint development. World development, 19 (4), 287 - 300.

Rogers, M. (2016). Problematising participatory video with youth in Canada: the intersection of therapeutic, deficit and individualising discourses. Area, 48(4), 427-434.

Shaw, J. (2016). Emergent ethics in participatory video: negotiating the inherent tensions as group processes evolve. Area, 48(4), 419-426.

Shaw, J. (2015). Re-grounding Participatory Video within community emergence towards social accountability. Community Development Journal, 4 (1), 624 - 643. 
Shaw, J. (2012). Contextualising empowerment practice: negotiating the path to becoming using participatory video processes. PhD thesis, The London School of Economics and Political Science (LSE), http://etheses.Ise.ac.uk/400/

Sillitoe, P. (Ed.) 2017. Indigenous knowledge: enhancing its contribution to natural resource management. Wallingford, Oxfordshire: CABI.

Waite, L. \& Conn, C. (2011). Creating a space for young women's voices: using 'participatory video drama' in Uganda. Gender, Place \& Culture: A Journal of Feminist Geography, 18 (1), 115 - 135.

Walsh, S. (2016). Critiquing the politics of participatory video and the dangerous romance of liberalism. Area, 48(4), 405-411.

Wheeler, J. (2011). Seeing like Citizen: Participatory Video and Action Research for Citizen Action. In: Digital (alter) natives with a cause?, Shaw, N. \& Jansen, F. (eds.)

White, S. C. (1996). Depoliticising development: the uses and abuses of participation. Development in practice, $6(1), 6-15$.

Wickett, E. (2007). Visual anthropology and development: Video as critique, praxis and process. Visual anthropology review, 23(1), 69-75. 
1

2

3

4

5

6

7

8

9

10

11

12

13

14

15

16

17

18

19

20

Wynne-Jones, S., North, P., \& Routledge, P. (2015). Practising participatory geographies: potentials, problems and politics. Area, 47(3), 218-221.

Zulu, L. C. (2010). The forbidden fuel: Charcoal, urban fuelwood demand and supply dynamics, community forest management and woodfuel policy in Malawi. Energy Policy, 38 (7), 3717-3730.

\footnotetext{
${ }^{1}$ Two of the authors are anthropologists with long-term experience in the project countries and the third has degrees in international development/agronomy.

${ }^{2}$ Indeed, farmers frequently cited lack of capital as a challenge to agricultural investment in discussions over the three-year project.
} 